\title{
Smoking cessation at the workplace. Results of a randomised controlled intervention study
}

T Lang, V Nicaud, K Slama, A Hirsch, E Imbernon, M Goldberg, L Calvel, P Desobry, J P Favre-Trosson, C Lhopital, P Mathevon, D Miara, A Miliani, F Panthier, G Pons, C Roitg, $M$ Thoores and the worksite physicians from the AIREL group
INSERM U258,

Villejuif, France

T Lang

V Nicaud

L Calvel

Union Internationale contre le tabac et les maladies respiratoires, Paris, France

K Slama

Hôpital Saint Louis, Paris, France

A Hirsch

Service général de Médecine du Travail, EDF-GDF, Paris,

France

E Imbernon

INSERM U88, Saint-Maurice, France M Goldberg

Services de Médecine du Travail EDF-GDF, France

P Desobry

J P Favre-Trosson

C Lhopital

P Mathevon

D Miara

A Miliani

F Panthier

G Pons

C Roitg

M Thoores

Correspondence to: Dr Lang, INSERM U258, Hôpital Paul Brousse, 16 Avenue Paul Vaillant Couturier, 94807 Villejuif, France

Accepted for publication 17 June 1999
Abstract

Objectives-To compare the effects of a worksite intervention by the occupational physician offering simple advice of smoking cessation with a more active strategy of advice including a "quit date" and extra support.

Population-Employees of an electrical and gas company seen at the annual visit by their occupational physicians.

Criteria end points-Smoking point prevalence defined as the percentage of smokers who were non-smokers at one year. Secondary criteria were the percentage of smokers who stopped smoking for more than six months and the difference in prevalence of smoking in both groups. Methods-Randomised controlled trial. The unit of randomisation was the work site physician and a random sample of the employees of whom he or she was in charge. The length of the follow up was one year. Each of 30 work site physicians included in the study 100 to 150 employees. Results-Among 504 subjects classified as smokers at baseline receiving simple advice (group A) and 591 the more active programme (group B), $68(13.5 \%)$ in group $A$ and 109 (18.4\%) were nonsmokers one year later $(p=0.03 ; p=0.01$ taking the occupational physician as the statistical unit and using a nonparametric test). Twenty three subjects $(4.6 \%)$ in group $A$ and $36(6.1 \%)$ in group B $(p=0.26)$ declared abstinence of six months or more. Among non-smokers at baseline, $3.4 \%$ in both groups were smokers after one year follow up. The prevalence of smokers did not differ significantly at baseline $(32.9 \%$ and $32.4 \%$, $\mathbf{p}=0.75$ ). After the intervention the prevalence of smoking was $30.8 \%$ in group $A$ and $28.7 \%$ in group $B(p=0.19)$. An increase of the mean symptoms score for depression in those who quit was observed during this period.

Conclusions-A simple cessation intervention strategy during a mandatory annual examination, targeting a population of smokers independently of their motivation to stop smoking or their health status, showed a $36 \%$ relative increase of the proportion of smokers who quit smoking as compared with what can be achieved through simple advice.

(F Epidemiol Community Health 2000;54:349-354)
Despite the major impact of smoking, responsible for a significant proportion of several leading causes of mortality, such as cardiovascular diseases, lung cancer and chronic bronchitis, ${ }^{1}$ the priority of smoking cessation has not yet ranked as high in medical activities as one might expect. Asking patients whether they smoke and advising them to quit is not common practice among physicians ${ }^{2}$ despite the evidence of efficacy of this practice. ${ }^{3-7}$ For example, less than $50 \%$ of smokers stated that their physicians had ever advised them to stop or reduce smoking. ${ }^{25}$ Physicians' practices have only slightly changed in recent years with respect to tobacco counselling. ${ }^{8}$

More attention has been paid to the pharmacological help to nicotine dependent smokers than to the potential benefits of simple advice by health personal given to a large number of smokers who may quit or consider quitting after such a simple advice. Indeed, the great majority of smokers report they have quitted without any formal programme to help them. ${ }^{9}$ Even if the success rates that can be expected by these mass strategies are much lower than those obtained among volunteers, the large numbers of potential quitters makes the mass strategy interesting from the population and public health point of view.

In France, among the worksite physician responsibilities is an annual mandatory examination of each employee they are in charge of. Approximately 10 to 12 million people can be reached through this approach, even those who do not visit a physician otherwise. As it has been suggested that education through media was much more effective when reinforced by personal contacts such as those between smokers and their physician, ${ }^{10}$ the potential benefits of advice given by the work site physician seem to be potentially important. The results of the most recent trials in this respect have been however inconsistent. ${ }^{911-14}$

The goal of our study was thus to evaluate the benefit that might be obtained if, in addition to simple advice of smoking cessation during the annual visit with the occupational physician, a strategy with a more active involvement of the worksite health personnel, offering a "quit date" and extra support for smoking cessation is provided.

\section{Methods}

DESIGN

A randomised controlled trial was organised to compare two smoking cessation strategies. The unit of randomisation was the work site physician and a random sample of the employees of 
whom he was in charge. Follow up occurred one year later at the annual work site mandatory examination.

The main criteria of the trial was the smoking point prevalence defined as the percentage of smokers who were non-smokers at one year. We also measured the prevalence of smoking in both groups, and percentage of smokers who sustained abstinence for six months and more.

RECRUITMENT OF THE WORK SITE PHYSICIANS

Among the 175 work site physicians of the French National Electricity and Gas Company, 35 expressed their interest in participating in the evaluation of a smoking cessation programme. Five had already undertaken programmes on an individual basis or did not want to be randomised. As a result, 30 work site physicians were included in the study.

INCLUSION OF THE SUBJECTS

Before randomisation, each work site physician sent the scientific committee a list of their working units (10 to 20 units per physician; 100 to 150 employees per unit). Then, one unit per physician was randomly selected among his or her units. After randomisation, the work site physician applied the strategy to which he was allocated for the entire population of the selected unit. Their inclusion and follow up at one year were performed during the annual mandatory examination at the work sites. All subjects were informed of the study and gave their consent. The study and the consent procedure were declared to the CNIL (Commission Nationale Informatique et Liberté).

\section{MEASUREMENTS}

Information on demographics, personal habits, working conditions, attitudes and behaviours were assessed through a self administered ad hoc questionnaire before the annual examination, in the waiting room. Clinical data were obtained by the work site physician during the same examination. Nicotin dependency was assessed by global self assessment ("do you feel dependent on tobacco smoking?") and the Fagerström score, a six items questionnaire based on smoking habits. ${ }^{15}$ Depression was assessed by a validated score, the French version of the CES-D self administered questionnaire. ${ }^{16}$

Smoking status was assessed by subject interview. Although self assessment of smoking status by subjects has been reported to be fairly reliable, ${ }^{17}{ }^{18}$ validation of smoking status was performed on a sub-group of the population, 897 subjects at inclusion and 657 at follow up, among who 231 were smokers at inclusion. This procedure was performed by a sub-sample of work site physicians who had the opportunity to use a carbon monoxide analyser. The threshold of carbon monoxyde expired used for calculations was $7 \mathrm{ppm}$, as it was found to provide a reliable indicator of smoking status. ${ }^{18}$

DESCRIPTION OF THE STRATEGIES

Strategy A was a 5 to 10 minutes intervention, given by the work site physician to self reported smokers. It included information about health and social consequences of tobacco smoking, as well as of cessation, answers to the most often asked questions in relation to the negative effects of smoking cessation, ${ }^{319}$ and advice to stop. A special training session was organised for the physicians included in the strategy A, independent of another training session for the physicians in strategy $B$.

Strategy B was a more active intervention. It was based on a contract proposed by the physicians to the smoker during the annual examination. The goal was to propose to the employees to actually begin the smoking cessation process. During the visit, the information provided to the smokers was the same as the information provided in group A. In addition, whenever accepted, a date was decided for smoking cessation in the month after the visit. This date was a sort of moral contract between the worker and the physician. Seven days after the planned date, a phone call was made to the smoker to reinforce or to encourage his decision. One to two months after the decision to stop smoking a second visit was organised to reinforce or encourage smokers who had stopped smoking, ex-smokers who relapsed and those who had not tried to stop. ${ }^{6}$

For both strategies, the medical team was composed of a physician and, whenever possible, the nurses who could reinforce the physician activity. Information, brochures and educational tools were provided to both groups.

\section{STATISTICAL ANALYSIS}

The trial was analysed on an intention to treat basis. As a result, subjects were included in the final analysis whether or not they decided to stop during the initial visit, agreed or not to decide a date for smoking cessation, and whether or not they returned to the one month visit. Smokers at baseline who refused to state their cigarette consumption or did not come to the annual examination one year later were classified as smokers at the end of the follow up period. Smokers lost to follow up for reasons related to the company were excluded from the analysis on follow up. The point prevalence of cessation was used as a main criterion because this measure could be validated using expired carbon monoxide as a gold standard. Self reported duration of the cessation is a main criteria as it takes into account the transitory nature of a large proportion of initial abstinence. However, this measure could not be validated. Percentages were compared using the $\chi^{2}$ test and means using the Student $t$ test. The statistical significance of the difference of treatment for cessation at one year was performed allowing for cluster randomisation. Occupational physician was used as the statistical unit and a non-parametric approach was used, based on the Mann-Whitney-Wilcoxon rank sum test. ${ }^{20}$ Data were analysed using the SAS statistical package. ${ }^{21}$

\section{Results}

INCLUSION AND FOLLOW UP

Thirty work site physicians were randomised into group A or B. In group A, two physicians declined participation after the randomisation process. Altogether, 13 physicians in group A 
Table 1 Inclusion and follow up

\begin{tabular}{|c|c|c|}
\hline & Strategy $A$ & Strategy $B$ \\
\hline & Number & Number \\
\hline Work site physicians & 13 & 15 \\
\hline \multicolumn{3}{|l|}{ Baseline } \\
\hline $\begin{array}{l}\text { Subjects at inclusion } \\
\text { among which: smokers }\end{array}$ & $\begin{array}{l}1773 \\
579(33 \%)\end{array}$ & $\begin{array}{l}2110 \\
690(33 \%)\end{array}$ \\
\hline \multicolumn{3}{|l|}{ After one year follow up } \\
\hline $\begin{array}{l}\text { Subjects at follow up } \\
\text { among which: smokers }\end{array}$ & $\begin{array}{l}1400 \\
448\end{array}$ & $\begin{array}{l}1752 \\
564\end{array}$ \\
\hline \multicolumn{3}{|l|}{ Lost to follow up } \\
\hline $\begin{array}{l}\text { in relation to company reorganisation } \\
\text { refusals }\end{array}$ & $243(14 \%)$ & $284(13 \%)$ \\
\hline among non-smokers at baseline & 74 & 47 \\
\hline among smokers at baseline & 56 & 27 \\
\hline $\begin{array}{l}\text { Smokers at follow up (smokers }+ \text { refusals among } \\
\text { smokers at baseline) }\end{array}$ & $504(87 \%)$ & $591(86 \%)$ \\
\hline
\end{tabular}

Table 2 Comparison of the two groups randomised into strategies $A$ (advice) and $B$ (proposal and support), at baseline

\begin{tabular}{llll}
\hline & & & \\
& Strategy $A$ & Strategy $B$ & $p^{*}$ \\
\hline Number & 579 & 690 & \\
Age (y) (mean (SD)) & $38.8(7.8)$ & $37.3(7.7)$ & $0.01(0.15)$ \\
Men & $83 \%$ & $82 \%$ & 0.63 \\
Living alone & $20 \%$ & $21 \%$ & 0.67 \\
Chronic cough & $16 \%$ & $12 \%$ & 0.07 \\
Dyspnea & $12 \%$ & $9 \%$ & 0.09 \\
Arterial hypertension & $12 \%$ & $6 \%$ & $<0.001(0.04)$ \\
Cholesterol screening (at least once) & $69 \%$ & $66 \%$ & 0.23 \\
Sports activity (weekly hours) & $2.9(3.1)$ & $3.2(3.7)$ & 0.12 \\
Alcohol (units/day) & $3.4(4.1)$ & $2.7(3.2)$ & $<0.001(0.006)$ \\
Psychotrop consumption & $12 \%$ & $7 \%$ & $<0.001(0.03)$ \\
Depressiont & $20.4 \%$ & $17.2 \%$ & 0.15 \\
CES-D score & $12.3(8.7)$ & $11.7(7.8)$ & 0.20 \\
Tobacco habits & & & \\
$\quad$ Cigarettes (number/day) & $13.9(9.6)$ & $14.7(9.9)$ & 0.15 \\
Heavy cigarettes smokers $\geqslant 10$ cig/day & $64.0 \%$ & $67.0 \%$ & 0.28 \\
Cigarillos (number/day) & $0.6(2.1)$ & $0.8(2.7)$ & 0.15 \\
Cigars (number/day) & $0.5(3.0)$ & $0.8(3.2)$ & 0.09 \\
$\quad$ Pipe (number/day) & $0.3(1.2)$ & $0.4(1.5)$ & 0.20 \\
Fagerstrom score & $4.1(2.1)$ & $4.2(2.1)$ & 0.40 \\
Self perceived dependency to tobacco & $59 \%$ & $67 \%$ & $<0.001(0.006)$ \\
Previous smoking cessation attempt? & $73 \%$ & $74 \%$ & 0.69 \\
Parental history of smoking & & & \\
Father & $83 \%$ & $84 \%$ & 0.64 \\
Mother & $14 \%$ & $19 \%$ & $<0.05(0.11)$ \\
Smoking spouse & $38 \%$ & $45 \%$ & $<0.05(0.03)$ \\
& & &
\end{tabular}

${ }^{*} \mathrm{p}$ values were computed using the individual as the statistical unit and ( $\mathrm{p}$ values) using the physician as the statistical unit. †Depression if score $\geqslant 17$ in men or $\geqslant 23$ for women.

Table 3 Validation of subjects statements as compared with expired carbon monoxide, in a sub-sample of the population

\begin{tabular}{|c|c|c|}
\hline & Strategy $A$ & Strategy $B$ \\
\hline \multicolumn{3}{|c|}{ Comparison between self reported smoking status and expired $\mathrm{CO} \geqslant 7 \mathrm{ppm}$} \\
\hline \multicolumn{3}{|c|}{ At inclusion, in the whole population } \\
\hline Number & 612 & 285 \\
\hline Concordance & 0.82 & 0.79 \\
\hline$\kappa$ coefficient $(95 \% \mathrm{CI})$ & $0.61(0.54,0.67)$ & $0.56(0.46,0.65)$ \\
\hline \multicolumn{3}{|c|}{ At one year follow up, among subjects who were smokers at inclusion } \\
\hline Number & 164 & 67 \\
\hline Concordance & 0.82 & 0.76 \\
\hline$\kappa$ coefficient $(95 \% \mathrm{CI})$ & $0.38(0.20,0.56)$ & $0.37(0.12,0.62)$ \\
\hline \multicolumn{3}{|c|}{ Among smokers, correlation between expired carbon monoxide and number of cigarettes/day ${ }^{\star}+$} \\
\hline \multicolumn{3}{|c|}{ Inclusion } \\
\hline Number & 205 & 98 \\
\hline$r$ & 0.57 & 0.51 \\
\hline $\mathrm{p}$ & $\mathrm{p}=0.0001$ & $\mathrm{p}=0.0001$ \\
\hline \multicolumn{3}{|l|}{ One year follow up } \\
\hline Number & 142 & 49 \\
\hline$r$ & 0.54 & 0.57 \\
\hline $\mathrm{p}$ & $\mathrm{p}=0.0001$ & $\mathrm{p}=0.0001$ \\
\hline
\end{tabular}

${ }^{\star}$ Given the skewness of the distribution, cigarette consumption was log transformed. †The consumption of occasional smokers ( $<1 \mathrm{cig} / \mathrm{day}$ ) was arbitrarily fixed at 0.2 cigarettes/day as many occasional smokers reported smoking 1 cig/week.

and 15 in group B included two populations of 1773 and 2110 men and women in the study (table 1). Among the 3883 subjects included, $527(13.6 \%)$ were lost to follow up for work related reasons (closure of a plant, change of workplace, etc). These subjects were excluded from the analysis on follow up. Their character- istics at baseline did not differ significantly from the other subjects. Another 204 (5.3\%) refused to participate, without any economic or work related reason. Among them, 83 were smokers at baseline and were thus defined as smokers at follow up.

COMPARISON OF GROUPS A AND B AT INCLUSION In group $\mathrm{A}$, subjects were older than in group $\mathrm{B}$ (mean (SD) 39.6 (8.0) years $v 38.2$ (7.9), $\mathrm{p}<0.001)$, the percentage of men was lower ( $75 \%$ v $79 \%, \mathrm{p}<0.001)$, the educational level was lower $(29 \%$ had a high school diploma $v$ $33 \%, \mathrm{p}<0.01)$ and the mean (SD) weekly sports activity was shorter (3.0 (3.1) v 3.3 (3.4), $\mathrm{p}<0.001)$. The percentage of smokers $(33 \%)$, ex-smokers (30\%) and non-smokers (37\%) did not differ between groups. Eighty nine per cent of subjects in group A and $92 \%$ in group B agreed that the work site physician could promote general prevention in addition to prevention of work related hazards $(\mathrm{p}<0.005)$.

COMPARISON OF SMOKERS IN GROUPS A AND B AT INCLUSION

Among smokers, age, prevalence of arterial hypertension, alcohol consumption and psychotropic drug use were lower in group B (table 2). Smoking behaviour and Fagerström dependence score did not differ between groups. Self assessed dependency was higher in group B. No differences were observed concerning other prevention attitudes: previous attempts of modifying nutrition ( $72 \%$ in both groups), increased sport activity (65\% in both groups). Educational level (high school diploma: $27 \%$ ), satisfaction at work, relationships with colleagues or hierarchy, working schedules and percentage of those who had gone through reorganisation of the job in the previous year did not differ between groups.

\section{VALIDATION OF SMOKING STATEMENTS}

Concordance between stated smoking status and expired carbon monoxide, as well as the correlation coefficient between the number of cigarettes per day as stated by the subject and the measured expired carbon monoxide was high and did not differ between groups $\mathrm{A}$ and $\mathrm{B}$ (table 3).

RESULTS OF THE TRIAL

Among 504 subjects classified as smokers at baseline in group A and 591 in group B, 68 $(13.5 \%)$ in group A and $109(18.4 \%)$ were non-smokers one year later $(p=0.03 ; p=0.01$ taking the occupational physician as the statistical unit and using a rank non-parametric test) (tables 4 and 5). Self reported sustained cessation of six months and more was reported in 23 subjects $(4.6 \%)$ in group A and $36(6.1 \%)$ in group B $(p=0.26)$. Among non-smokers at baseline, $3.4 \%$ in both groups were smokers after one year follow up.

PREVALENCE OF SMOKING

The prevalence of smokers did not differ significantly at baseline (32.9 and $32.4 \%$, $\mathrm{p}=0.75)$. After the intervention the prevalence of smoking decreased in both groups: $-6.4 \%$ 
Table 4 Follow up and smoking cessation by physician

\begin{tabular}{|c|c|c|c|c|c|c|}
\hline \multicolumn{2}{|l|}{ Inclusion } & \multicolumn{5}{|c|}{ One year follow up } \\
\hline $\begin{array}{l}\text { Work site } \\
\text { physicians }\end{array}$ & $\begin{array}{l}\text { Smokers } \\
\text { included }\end{array}$ & $\begin{array}{l}\text { Follow up } \\
\text { impossible for } \\
\text { reasons related } \\
\text { to the } \\
\text { company }\end{array}$ & $\begin{array}{l}\text { Refusals } \\
\text { (a) }\end{array}$ & $\begin{array}{l}\text { Self reported } \\
\text { non-smokers } \\
\text { (b) }\end{array}$ & $\begin{array}{l}\text { Self } \\
\text { reported } \\
\text { smokers } \\
\text { (c) }\end{array}$ & $\begin{array}{l}\text { Smoking } \\
\text { cessation } \\
(b / a+b+c)\end{array}$ \\
\hline Strategy $A$ & Number & Number & Number & Number & Number & $\%$ \\
\hline 1 & 66 & 4 & 12 & 9 & 41 & 14.5 \\
\hline 2 & 55 & 5 & 13 & 3 & 34 & 6.0 \\
\hline 3 & 19 & 0 & 6 & 0 & 13 & 0 \\
\hline 4 & 59 & 13 & 3 & 8 & 35 & 17.4 \\
\hline 5 & 19 & 8 & 0 & 0 & 11 & 0 \\
\hline 6 & 35 & 7 & 0 & 5 & 23 & 17.9 \\
\hline 7 & 56 & 3 & 9 & 9 & 35 & 17.0 \\
\hline 8 & 75 & 7 & 9 & 8 & 51 & 11.8 \\
\hline 9 & 30 & 1 & 0 & 5 & 24 & 17.2 \\
\hline 10 & 38 & 2 & 2 & 6 & 28 & 16.7 \\
\hline 11 & 32 & 2 & 2 & 4 & 24 & 13.3 \\
\hline 12 & 38 & 14 & 0 & 4 & 20 & 16.7 \\
\hline 13 & 57 & 9 & 0 & 7 & 41 & 14.6 \\
\hline Total & 579 & 75 & 56 & 68 & 380 & 13.5 \\
\hline \multicolumn{7}{|l|}{ Strategy $B$} \\
\hline 1 & 63 & 5 & 0 & 11 & 47 & 19.0 \\
\hline 2 & 63 & 12 & 0 & 12 & 39 & 23.5 \\
\hline 3 & 30 & 4 & 0 & 8 & 18 & 30.8 \\
\hline 4 & 35 & 2 & 2 & 9 & 22 & 27.3 \\
\hline 5 & 55 & 5 & 1 & 7 & 42 & 14.0 \\
\hline 6 & 36 & 1 & 0 & 8 & 27 & 22.9 \\
\hline 7 & 39 & 19 & 0 & 6 & 14 & 30.0 \\
\hline 8 & 43 & 9 & 2 & 6 & 26 & 17.6 \\
\hline 9 & 41 & 2 & 0 & 9 & 30 & 23.1 \\
\hline 10 & 39 & 12 & 2 & 6 & 19 & 22.2 \\
\hline 11 & 53 & 10 & 10 & 6 & 27 & 13.9 \\
\hline 12 & 33 & 3 & 6 & 2 & 22 & 6.7 \\
\hline 13 & 57 & 2 & 0 & 9 & 46 & 16.4 \\
\hline 14 & 40 & 1 & 2 & 7 & 30 & 17.9 \\
\hline 15 & 63 & 12 & 2 & 3 & 46 & 5.9 \\
\hline Total & 690 & 99 & 27 & 109 & 455 & 18.4 \\
\hline
\end{tabular}

Table 5 Smoking prevalence in both groups after one year follow up

\begin{tabular}{|c|c|c|c|}
\hline Strategies & $A$ & $B$ & $p$ \\
\hline \multicolumn{4}{|l|}{ Smoking prevalence } \\
\hline Inclusion (baseline) & $504 / 1530(32.9 \%)$ & $591 / 1826(32.4 \%)$ & \\
\hline One year (follow up) $)^{\star}$ & $471 / 1530(30.8 \%)$ & $524 / 1826(28.7 \%)$ & \\
\hline Difference baseline follow up & $2.1 \%$ & $3.7 \%$ & \\
\hline \multirow{2}{*}{\multicolumn{4}{|c|}{$\begin{array}{l}\mathrm{P} \text { Smokers at one year } \\
\text { Pmo }\end{array}$}} \\
\hline & & & \\
\hline $\begin{array}{l}\text { Among non-smokers at inclusion } \\
\text { Non-smokers at one year }\end{array}$ & $35 / 1026(3.4 \%)$ & $42 / 1235(3.4 \%)$ & 0.98 \\
\hline $\begin{array}{l}\text { Among smokers at inclusion } \\
\text { Length of cessation }\end{array}$ & $68 / 504(13.5 \%)$ & 109/591 (18.4\%) & $0.03 \dagger$ \\
\hline Smokers & $436(86.5 \%)$ & $482(81.6 \%)$ & \\
\hline Cessation $<6$ months or undetermined & $45(8.9 \%)$ & $73(12.3 \%)$ & \\
\hline Cessation $\geqslant 6$ months & $23(4.6 \%)$ & $36(6.1 \%)$ & $0.26 \ddagger$ \\
\hline
\end{tabular}

${ }^{\star}$ Considering all non-respondent (smokers and non-smokers at baseline) as smokers at follow up, prevalence of smoking would be 545/1530 (35.6\%) in group A and 571/1826 (31.3\%) in group B. $\dagger$ Taking into an account the randomisation by cluster: non-parametric Mann-Whitney test: $\mathrm{p}=0.01$. $\ddagger$ Grouping smokers and cessation $<6$ months.

Table 6 Depression and body mass index after smoking cessation

\begin{tabular}{|c|c|c|c|c|}
\hline & \multicolumn{4}{|c|}{ Difference between value at one year and at inclusion } \\
\hline & \multicolumn{2}{|l|}{ Strategy $A$} & \multicolumn{2}{|c|}{ Strategy $B$} \\
\hline \multicolumn{5}{|l|}{$\begin{array}{l}\text { Body mass index }\left(\mathrm{kg} / \mathrm{m}^{2}\right) \\
\text { Non-smokers at one year }\end{array}$} \\
\hline follow up & $1.5(3.4)$ & & & $1.7(3.4)$ \\
\hline Smokers at one year follow up & $448 \quad 0.6(4.7)$ & & 564 & $0.8(8.4)$ \\
\hline $\begin{array}{l}\text { Statistical effects: } \\
\text { Depression score (CES-D) }\end{array}$ & Smoking, $p=0.13$ & strategy, $\mathrm{p}=0.56$ & interac & ion, $\mathrm{p}=0.80$ \\
\hline Non-smokers at one year & & & & \\
\hline follow up & $0.7(5.6)$ & & 82 & $1.4(8.5)$ \\
\hline Smokers at one year follow up & $338-1.1(7.6)$ & & 361 & $-0.4(6.3)$ \\
\hline Statistical effects: & Smoking, $\mathrm{p}=0.007$ & strategy, $\mathrm{p}=0.27$ & interact & ion, $\mathrm{p}=0.99$ \\
\hline
\end{tabular}

Data shown as mean (SD).
SUBGROUPS

The effect of the strategy was similar for both sexes. Strategy B was more effective than strategy A among moderate smokers $\quad<10$ cigarettes/ day), $31.4 \%$ versus $16.8 \%$, than among heavy smokers ( $\geqslant 10 \mathrm{cig} /$ day), $12.2 \%$ versus $11.6 \%$ (homogeneity of odds ratio: $\mathrm{p}=0.028)$. It was also more effective among subjects aged 40 and more $(19.0 \% v 9.8 \%)$ than among younger subjects $(18.1 \%$ v $16.7 \%$ ), (homogeneity of odds ratio: $p=0.06$ ). Among subjects who reported low control over their own health strategy B produced a better cessation rate $(21.2 \% v 8.7 \%)$; among others the difference in results was minor $(17.5 \% v$ $15.5 \%$ ) (homogeneity of odds ratio: $\mathrm{p}=0.06$ ).

CONSEQUENCES OF SMOKING CESSATION

Alcohol consumption, systolic and diastolic blood pressure, perceived health did not change with smoking cessation in any group. In contrast, there was a tendency for an increase in body mass index and a statistically significant increase in CES-D score among subjects who stopped smoking. No interaction with strategy was observed (table 6).

\section{Discussion}

A brief face to face intervention on the work site, providing support and help for quitting smoking gave a $36 \%$ higher cessation rate than a simple advice intervention by the occupational physician. In absolute terms $5 \%$ of smokers were quitters one year later as a result of this strategy based on health personnel advice and support. These results were based respectively on the ratio and the difference in point prevalence of quitters between groups. They were concordant with the results on long term quitting, which, although statistically non-significant, was 33\% higher when support was added to advice. The incidence of non-smokers or ex-smokers relapse was the same in both groups, so the prevalence of smoking decreased in the group with minimal intervention after advice. The effect of the strategy combining advice and support was greatest among smokers with low cigarette consumption and it helped mostly smokers over 40 years of age and those who had the lowest feeling of control over their health. In contrast, the effect did not differ between genders.

Some limits of the study should be kept in mind. Point prevalence does not measure long term smoking cessation. However, self reported point prevalence could be controlled by expired carbon monoxide. Its validity did not differ between groups. Occupational exposures to carbon monoxide might decrease the intensity of the observed association. It is unlikely that they could create a spurious association. This study thus accurately estimates the relative effect $(+36 \%)$ but not the absolute smoking cessation rate. In light of the "sleeper" effectthat is, the fact that some smokers may listen to the advice, but may not act immediately until being triggered some time later by a another intercurrent event, for example a respiratory infection, ${ }^{19}$ - this measure is however a good indicator of the relative effectiveness of the

intervention. Contamination between groups
There was a larger but non-significant difference between group A $(30.8 \%)$ and group B $(28.7 \%)(\mathrm{p}=0.19)$. 
was probably low in this study because work sites of the participating physicians were geographically distinct, so that workers had very few interactions. A higher loss to follow up rate because of refusals was observed in group A. These refusals were assumed to still be smoking. The true quit rate in group A was thus underestimated. However, if the quit rate among these refusals is assumed to be the same as among other subjects, the outcome in group $B$ would still be better. Although the experimental design measures the comparative effectiveness of strategy based on support and advice compared with advice alone, it is not possible to identify the component of the intervention that accounts for the results: a concrete proposal for action for smoking cessation, a reminder telephone call, social support, etc.

Although no economic study was performed in this trial, the cost effectiveness of the intervention is probably low, ${ }^{7}$ as in the context of the work site of a large sized company, the visit is already mandatory and additional support is feasible at low cost. The feasibility of this intervention in the context of small sized companies where the physician is not "on site" but deals with several small sized companies may be more problematic. In those conditions, additional visits might be somewhat difficult to organise. Another question is to know whether this intervention is feasible in routine practice. In this study, the intervention was found to be quite acceptable and even welcomed by the company employees. Participating physicians were likely to be more enthusiastic and knowledgeable about smoking prevention than other physicians. This might change the absolute percentage of quitters in other settings, but not the relative effect of the two strategies.

Brief training and intervention protocols by physicians have prompted cessation rates up to $15 \%$, defined as the percentage of smoke free patients at one year among smokers at the beginning of the study. ${ }^{6}$ Surprisingly, our results are concordant with those observed in general practice. Simple advice given by a physician yields a $2 \%$ difference in cessation rate as compared with control group without any intervention $^{7}$ and additional encouragement/ support compared with this simple advice produces an additional 5\% difference. ${ }^{7}$ In contrast, results obtained in a work site population of unmotivated smokers should not be compared with results among special groups (in pregnancy, $8 \%$; among myocardial infarction survivors, $36 \%$; or subjects at high risk of heart disease, $21 \%$ ), nor with results among self referred patients treated with nicotine gum $(11 \%)$ or patch $(13 \%) .{ }^{7}$ In this respect, it is important to keep in mind the participation rate. For example, Clavel had to contact 280000 households to find 1320 volunteers to participate in a trial on smoking cessation methods. ${ }^{22}$

Our results concord with reports on the effectiveness of work site smoking cessation programmes. In particular they concord with quitting rates reported in a meta analysis of work site intervention programmes. ${ }^{23}$ Evaluations published later have been less
KEY POINTS

- In a randomised controlled study, providing minimal support for smoking cessation by the work site physician, in comparison with a simple advice, was found to increase the effects of their intervention.

- Although the results in absolute percentages are modest, they have a major public health impact because they concern an entire population of smokers, including those who have never considered quitting tobacco smoking.

- This study provides evidence that the benefits of the intervention of the work site physician on smoking cessation are potentially important.

conclusive. ${ }^{12-14}$ These interventions were multifactorial, which might explain the negative results on smoking, but the reasons for these conflicting results are still unclear. It is worth noting that, as in the COMMIT study, the intensive strategy was more effective on light and moderate smokers than on heavy smokers, ${ }^{13}$ as might be expected. More importantly, the results showed the importance of support for smokers who do have low perceived control over their health, and so are less likely to have stopped on their own.

Although the results expressed as absolute percentage $(5 \%)$ or relative (cessation rate $36 \%$ higher than with a simple advice) might seem modest, applied to the approximated 4.2 million salaried personnel in France who smoke, the impact of even modest results are worthwhile in terms of public health. Indeed, in a random sample of employees, around 50\% reported to have reduced smoking on weekends as well as on weekdays as a results of a work site smoking policy. ${ }^{24}$

Measuring cessation at one year follow up provides a fair estimate of the relative effectiveness of one strategy over another, but it is a poor measure of the health consequences of the intervention. Indeed, this intervention is directed toward all categories of smokers, including persons who are not even considering stopping, some who are thinking about it, those planning to stop and those who are already trying, as well as those who have recently relapsed..$^{25}$

Individual counselling is not the only approach to anti-smoking action, which should be seen in a broad societal view, thus implying political involvement in banning cigarette smoking. However, personal advice and face to face intervention have been shown to reinforce the results of media intervention. ${ }^{26}$ Cardiovascular risk reduction in the Stanford Three Cities Project was largely attributable to smoking cessation rates differences. ${ }^{27}$ In the UK multifactorial WHO intervention, smoking was the main risk factor modified and this effect was particularly observed among subjects who received face to face advice or counselling. ${ }^{10}$

The effectiveness of the intervention can also be confirmed by the comparison of the results 
of both interventions (simple and reinforced) with the natural trends of smoking in the GAZEL cohort, a cohort of 20000 volunteers from the same National Electricity and Gas Company (personal communication). Among this selected population, prevalence of smoking was lower than in our population. However it was stable: $22 \%$ in 1993 and $21 \% 1995$ in men, $15 \%$ at both periods in women (personal communication). The percentages of smokers who were non-smokers one year later were $11 \%$ in 1993 and $13 \%$ in 1995 in men and respectively 10 and $14 \%$ in women (personal communication). The stability of prevalence in the cohort and the lower quit rate, which was comparable to the advice only intervention, support the enhanced effectiveness of the reinforced intervention.

After smoking cessation, as expected, a tendency for weight increase was observed. ${ }^{28}$ Alcohol consumption, blood pressure and perceived health were not changed. In contrast, smoking cessation was significantly associated with an increase in depressive symptoms score (CES-D). ${ }^{16}$ These findings should be emphasised. Indeed, case reports have been published, describing major depressive symptoms after smoking cessation. ${ }^{29}$ Two prospective studies have reported development of major depressive disorder after smoking cessation among persons with a history of depression or scoring high on depressive mood at baseline. ${ }^{29-31}$ The occupational physician might consider the aid that can be suggested to combat this undesired contingency.

In conclusion, a simple intervention during a mandatory annual examination was shown to be effective, in a population of smokers of varying motivation to stop smoking or health status. Potential benefits were shown to be an additional $5 \%$ of smokers who quit and a relative increase of $36 \%$ of smoking cessation rate compared with simple advice. Negative effects of smoking cessation in this study were weight gain and depression. In our study, an increase of the mean symptoms score for depression was observed, which reinforces the need for social support during this period of smoking cessation. The modest cessation rate increased by this strategy is valuable for the people involved and for public health given the large number of potentially concerned smokers and the marginal costs of this strategy.

The AIREL Group: Dr B Boudin, J Nussbaum, P Betis, S Chevalier, Dr C Boyer, S Morel, Dr J-P Buzin, C Fauquet, C Lefaux, Dr H Champenier, M Guillot, A Andrieux, Dr Y Conti, C Thomas, M Jobin, Dr M Couzinet, S Pawlowski, M Gaillard, Dr S Creux, Dr P Desobry, Dr Chevalier, B Duhamel, M-C Fanien, Dr M Dessery, V Jouanne, J Deglin, Dr P Ducos, F Frasse, Dr A Ferron, Dr D Brochard, Mme Prévost, Mme O'Brien, Dr A Foveau, A-M Guthmann, M Canteri, Dr S Fromont-Ithurbide, Dr Martine, M Lestoclet, M-T Fauquet, Dr Y Garcier, M Legall, Dr F Giraud, N Hahn, C Gibault, Dr B Landry, Mme Rabikowski, C Lhopital, Mme Magnier, Dr P Mathevon, E Jayet, Dr B Melan, Mme Doche, Dr D Miara, C De Donker, T Maurot, Dr A Miliani, Dr A Gallet, A Quillay, Dr M Millet, C Lascaux, R Burel, Dr A Ozoux, Dr F Panthier, M Roby, B Lemeur-Pepay, Dr G Pons, D Aguergaray, L Delrue, Dr Roby, B Lemeur-Pepay, Dr G Pons, D Aguergaray, L Lelrue, Dr Mme Moureau, Dr C Roitg, R Bernot, Dr E Roux, F Lefevvre, S Martinelli, Dr B Strasman, Dr M Thiebot, M Zemliakoff, Dr G Warret, F Mourrier.
Funding: this study was made possible by financial support from INSERM (Institut National de la Santé et de la Recherche Médicale) and EDF-GDF (Electricité et Gaz de France).

Conflicts of interest: none.

1 Peto R, Lopez AD, Boreham J, et al. Mortality from tobacco in developed countries: indirect estimation from national vital statistics. Lancet 1992;339:1268-78.

2 Frank E, Winkleby MA, Altman DG, et al. Predictors of physicians' smoking advice. FAMA 1991;266:3139-44.

3 Slama K, Karsenty S, Hirsch A. Effectiveness of minimal intervention by general practitioners with their smoking patients : a randomised, controlled trial in France. Tobacco Control 1995;4:162-9.

4 Richmond RI, Austin A, Webster IW. Three year evaluation of a programme by general practitioners to help patients stop smoking. BMF 1986;292:803-6.

5 Cohen SJ, Stookey GK, Katz BP, et al. Encouraging primary care physicians to help smokers quit. Ann Intern Med 1989; 110:648-52.

6 Manley M, Epps RP, Husten C, et al. Clinical interventions in tobacco control. A National Cancer Institute training program for physicians. FAMA 1991;266:3172-3.

program for physicians. $\mathcal{F A M A} 1991 ; 266: 3172-3$.
7 Law M, Tang JL. An analysis of the effectiveness of $\mathrm{Law} \mathrm{M}$, Tang JL. An analysis of the effectiveness of
interventions intended to help people stop smoking. Arch Intern Med 1995;155:1933-41

8 Thorndike AN, Rigotti NA, Stafford RS, Singer DE. National patterns in the treatment of smokers by physicians. FAMA 1998;279:604-8.

9 Lichtenstein EL. Behavioral research contributions and needs in cancer prevention and control: tobacco use prevention and cessation. Prev Med 1997;26:S57-63.

10 Bauer RL, Heller RF, Challah S. United Kingdom Heart Disease Prevention Project: 12-year follow-up of risk factors. Am $\mathcal{F}$ Epidemiol 1985;121:563-9

11 Sorensen G, Thompson B, Glanz K, et al. Work site-based cancer prevention: primary results from the Working Well Trial. Am f Public Health 1996;86:939-47.

12 Community Intervention Trial for Smoking Cessation (COMMIT): I. cohort results from a four-year community intervention. Am f Public Health 1995;85:183-92.

13 Community intervention trial for smoking cessation (COMMIT): II. Changes in adult cigarette smoking prevalence. Am f Public Health 1995;85:193-200.

14 Glasgow RE, Terborg JR, Hollis JF, et al. Take heart: results from the initial phase of a work-site wellness program. Am f Public Health 1995;85:209-16

15 Fagerstrom KO, Shneider NG. Measuring nicotine dependence: A review of the Fagerstrom tolerance questionnaire. F Behav Med 1989;12:159-82.

16 Fuhrer R, Rouillon F. La version française de l'échelle CES-D (Center for Epidemiologic Studies-Depression Scale). Description et traduction de l'échelle d'autoévaluation. Psychiatr Psychobiol 1989;4:163-6.

17 Murray RP, Connett JE, Lauger GG, et al. Error in smoking measures: effects of intervention on relations of cotinine and carbon monoxide to self-reported smoking. The Lung Health Study Research Group. Am $\mathcal{f}$ Public Health Health Study R

18 Waage H, Silsand T, Urdal P, et al. Discrimination of smoking status by thiocyanate and cotinine in serum, and carbon monoxide in expired air. Int f Epidemiol 1992;21:488-93.

9 Wilson DH, Wakefield MA, Steven ID, et al. "Sick of smoking": evaluation of a targeted minimal smoking cessation intervention in general practice. Med $\mathcal{f}$ Austr 1990;152:518-21.

20 Donner A, Klar N. Methods for comparing event rates in intervention studies when the unit of allocation is a cluster. Am 7 Epidemiol 1994;140:279-89.

21 SAS/STAT. User's guide. Version 6. 4th ed. Cary, NC: SAS institute Inc, 1989.

22 Clavel-Chapelon F, Paoletti C, Benhamou S. A randomised $2 \times 2$ factorial design to evaluate different smoking cessation 2x2 factorial design to evaluate different smoking ces
methods. Rev Epidemiol Santé Publ 1992;40:187-90.

23 Fisher KJ, Glasgow RE, Terborg JR. Worksite smoking cessation: a meta-analysis of long-term quit rates from controlled studies. F Occup Med 1990;32:429-39.

24 Kinne S, Kristal AR, White E, et al. Work-site smoking policies-their population impact in Washington State. Am $\mathcal{F}$ Publ Health 1993;83:1031-3.

25 Prochaska J, DiClemente C. Stages and processes of self-change in smoking: toward an integrative model of change. $\mathcal{F}$ Consult Clin Psychol 1983;51:390-5.

26 Kottke TE, Battista RN, DeFriese H, et al. Attributes of successful smoking cessation interventions in medical practice. $¥ A M A$ 1988;259:2882-9.

27 Farquhar JW. The community-based model of life style intervention trials. Am $\mathcal{F}$ Epidemiol 1978;108:103-11.

28 Rigotti NA. Cigarette smoking and body weight. $N$ Engl f Med 1989;319:931-3.

29 Stage KB, Glassman AH, Covey LS. Depression after smoking cessation: case reports. f Clin Psychiatry 1996;57: 467-9.

30 Borrelli B, Niaura R, Keuthen NJ, et al. Development of major depressive disorder during smoking-cessation treatment. F Clin Psychiatry 1996;57:534-8.

31 Covey LS, Glassman AH, Stetner F. Major depression following smoking cessation. Am f Psychiatry 1997;154: $263-5$. 